\title{
Selective Copper Plating of Polysilicon Surface Micromachined Structures
}

\author{
Jer-Liang Andrew Yeh, Jia-Ming Chen, Tom Kudrle, Hercules P. Neves, and Norman C. Tien \\ School of Electrical Engineering, Comell University \\ 401 Philips Hall, Ithaca, NY 14853
}

\begin{abstract}
Selective electroless copper plating of polysilicon surface micromachined structures has been demonstrated. The encapsulation of free-standing polysilicon structures with copper will allow polysilicon to be used in MEMS applications requiring high conductivity. This copper deposition technique has the advantages of simplifying the metallization process, high deposition rate, low thermal stress, low bending stress, and backside metal coating. Palladium is used as the activated base metal for copper plating. Resisitivity and surface roughness characteristics of the copper are presented.
\end{abstract}

\section{INTRODUCTION}

Many microelectromechanical systems (MEMS) applications need metal structures for their electrical or optical properties. In wireless communication systems, components such as mechanical switches or high-Q passive elements require the high conductivity only available with metals. For instance, aluminum surface micromachining was used recently to fabricate a variable air-gap capacitor [1]. For optical systems, elements such as mirrors use metal because of their high reflectivity. Texas Instruments' Digital Mirror Device for projection displays [2] also uses aluminum structures.

There are, however, manufacturing challenges in using metal structures. One major difficulty is controlling the stress in metal films which causes bending of the structure. This leads to a restriction on the size of the element sometimes to less than 200 $\mu \mathrm{m}$ in any dimension [1]. Warping in these structures can be caused by the thermal mismatch between the metal and the sacrificial layer, which is usually photoresist or polyimide. Polysilicon surface micromachining, on the other hand, is a more mature technology that has demonstrated the ability to create not only larger-size low-stress structures, but also complex multi-level components. The drawback is that the electrical resistivity is higher and the optical reflectivity is lower for polysilicon when compared to most metals. Metallization of the polysilicon improves the electrical and optical characteristics. The typical procedure involves metal deposition (evaporation or sputtering) on the top of the polysilicon. This, however, results in a bimorph structure that could lead to warpage. Another metallization technique is electroless metal deposition $[3,4]$. Copper deposition on single-crystal silicon micromachined structures using an electroless plating technique [5] has been recently demonstrated.

Using this technique, we have selectively encapsulated polysilicon structures with copper, intended for use in wireless communication systems and in silicon micro-optical benches. Copper has a higher conductivity than aluminum which makes it attractive for high-Q RF elements. This method is compatible with silicon integrated circuit fabrication as copper will likely be used in future generations of integrated-circuit interconnects.

The copper deposition is a low-temperature process that minimizes the thermal stresses between itself and the polysilicon. Furthermore, copper deposited on both the top and backside of a structure is apt to balance the bending stress caused by copper plating the topside only. The encapsulation of a polysilicon cantilever has been demonstrated, shown in Figure 1.

The method has also been used to deposit copper on both sides of a hinged plate that can be used in silicon micro-optical systems, shown in Figure 2. A reflective surface on the backside of structures would allow more design flexibility, particularly for the hinged or folded-up optical elements used in the free-space micro-optical bench on silicon [6,7]. For instance, system design may require a hinged diffraction grating [8], with only topside metallization to be rotated to angles greater than $90^{\circ}$, which presents a difficult challenge for many actuators.

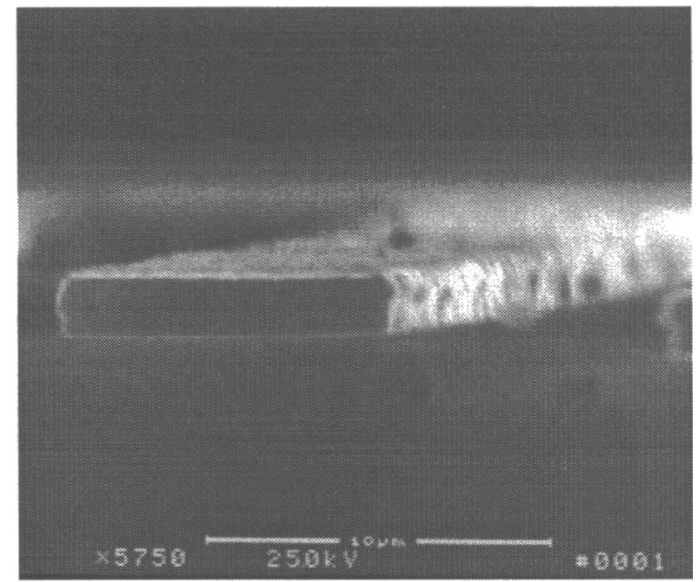

Figure 1: Cross section of a $1 \mathrm{~mm}$ long polysilicon beam. Approximately $0.2 \mu \mathrm{m}$ of copper is deposited on the whole surface of polysilicon.

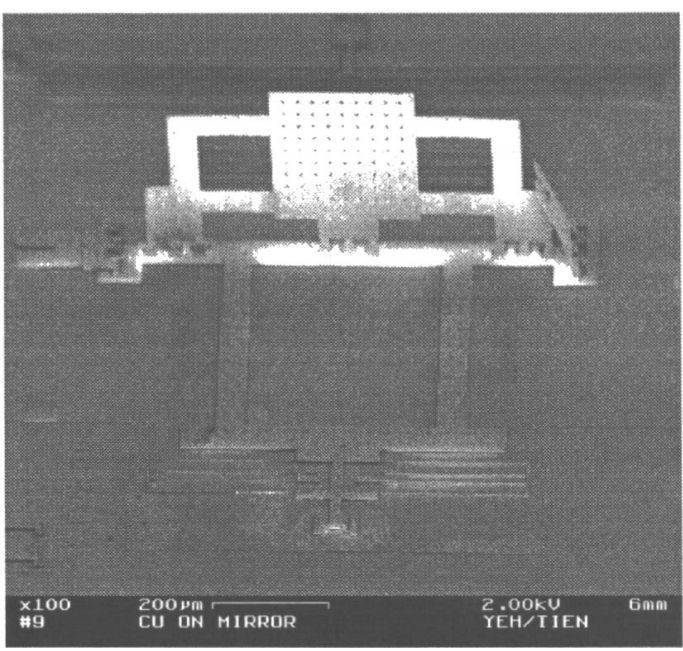

Figure 2: Backside of a flipped-up hinged polysilicon plate encapsulated in copper. 
This metallization method also simplifies the polysilicon surface micromachining fabrication process. Etching or lift-off of the metal is not required because the copper only deposits on the layers that are activated which in this case is polysilicon and not isolation layers such as nitride and oxide. The need for a metal photolithography step over the large topography commonly in three or four layer polysilicon surface micromachining is avofided.

Copper is not the only metal that can be used for selective electroless plating of polysilicon surface micromachined structures. Some ferretic metals such as iron $(\mathrm{Fe})$, nickle $(\mathrm{Ni})$, cobalt (Co) are also can be selectively deposited on polysilicon through palladium activation. In this paper, copper is used to demonstrated how this electroless plating process is applied to polysilicon surface micromachined structures.

\section{BASICS OF SELECTIVE ELECTROLESS COPPER PLATING}

Selective copper deposition [4] starts with wet activation on the surface of polysilicon. Through the mechanism of contact displacement between a catalytic metal and silicon, catalytic metal (palladium) is used to form an activated film on the silicon surface and not on the isolation layers such as silicon dioxide or silicon nitride. The native oxide on silicon surface is removed by diluted HF. For our work, palladium plays the role of a base metal for copper deposition, while silicon dioxide and silicon nitride stay inactive to either catalytic metal or copper during the deposition.

The electroless copper plating occurs in the temperature range of $55^{\circ} \mathrm{C}$ to $80^{\circ} \mathrm{C}$ and at a pH value ranging from 12 to 13 . The deposition process in a formaldehyde-based plating solution is well documented $[3,4]$. Our solution contains a cupric salt, a reducing agent (formadelhyde), and a complexing agent (Ethylenediaminetetraacetic acid, EDTA) to keep the cupric ions in solution. The basic reaction can be expressed as

$$
\mathrm{Cu}^{2+}+2 \mathrm{HCHO}+4 \mathrm{OH}^{-}=\mathrm{Cu}+\mathrm{H}_{2}+2 \mathrm{H}_{2} \mathrm{O}+2 \mathrm{HCOO}^{-}
$$

Additives to electroless $\mathrm{Cu}$ deposition solutions are surfactant RE610, surfactant/stabilizer $\operatorname{Triton}^{\circledR} \mathrm{X}-100$, and stabilizer 2,2'-dipyridyl. The surfactant RE610 is added to make copper surface smooth and give it a shining appearance. Triton ${ }^{\circledR}$ reduces defect density and enhances the electrical uniformity of $\mathrm{Cu}$ films. On the other hand, stabilizers decrease the deposition rate. A more detailed description of this technique will be published by Neves, H. P. et al. [9].

\section{EXPERIMENTAL PROCESS AND RESULT}

The test devices fabricated at the Cornell Nanofabrication Facility (CNF) follow a conventional three-layer polysilicon surface micromachining process. At CNF, we use a ptype LPCVD (low pressure chemical vapor deposition) polysilicon deposited at the temperature of $610^{\circ} \mathrm{C}$ as the structural material and a LPCVD low-temperature oxide deposited at the temperature of $400^{\circ} \mathrm{C}$ as the sacrificial layer. The p-type polysilicon is in-situ doped using $\mathrm{B}_{2} \mathrm{H}_{6}$ (diborane) as the boron source. This polysilicon surface micromachining process begins with the passivation layer including $0.5 \mu \mathrm{m}$-thick thermal oxide and $0.2 \mu \mathrm{m}$-thick LPCVD nitride.

The next steps involve deposition and definition of the ground polysilicon layer of thickness of $0.5 \mu \mathrm{m}$. This layer is lithographically patterned and then etched by a chlorine-based reactive-ion etch (RIE). A $2 \mu \mathrm{m}$-thick low-temperature oxide (LTO) is deposited as the first sacrificial layer and followed by lithographic patterning and a $\mathrm{CHF}_{3}$-based plasma etch of dimples and anchor openings. Another $2 \mu \mathrm{m}$-thick in-situ boron-doped polysilicon layer that acts as the first structural material is deposited and patterned. An annealing step is performed at $1000^{\circ} \mathrm{C}$ for one hour in $\mathrm{N}_{2}$. The second LPCVD LTO sacrificial layer of a thickness of $1.2 \mu \mathrm{m}$ is patterned and etched for the formation of anchor openings and polyl-poly2-vias. The last step of fabrication is to deposit and to pattern the $2 \mu \mathrm{m}$-thick second structural polysilicon layer.

Post-process primarily includes a hydrofluoric acid (HF) release, copper metallization, and self-assembly monolayer (SAM) coating to reduce stiction. First, the polysilicon structures are released by removing the sacrificial oxide with $49 \%$ hydrofluoric acid, HF, and then followed by deionized (DI) water rinse. The samples are kept in DI to prevent the stiction of the structures on to the substrate or with each other which commonly occurs when they are dried. Then, the samples are transferred to a palladium solution that selectively activates the polysilicon structures (on all sides) and initiates the autocatalytic electroless copper deposition. During the activation, both the sacrificial layer (oxide) and the passivation layer (nitride) remain inactive to palladium ions. Right after the activation on the surface of polysilicon, samples are immersed in a copper plating solution. At a temperature between $55-80^{\circ} \mathrm{C}$, the copper nuclei are initially formed on the $\mathrm{Pd}^{+}$. activated polysilicon surface. After the formation of a thin-layer copper, copper starts to deposit on this thin initiated copper film. Upon completion of the deposition, samples are coated with a selfassembled monolayer of octadecyltrichlorosilane ( $C^{18}$ OTS) in a process developed by Houston et al. to prevent stiction [10]

Alternatively, copper may also be selectively deposited in only certain regions on the chip. Before the HF release, photoresist is applied to the wafer. A photolithography step is used to open the areas where copper is to be deposited. After the buffered HF release of these areas, the photoresist is removed and is followed by the copper deposition. The sacrificial oxide prevents copper from depositing anywhere but released polysilicon regions (Figures 3 and 4 ).

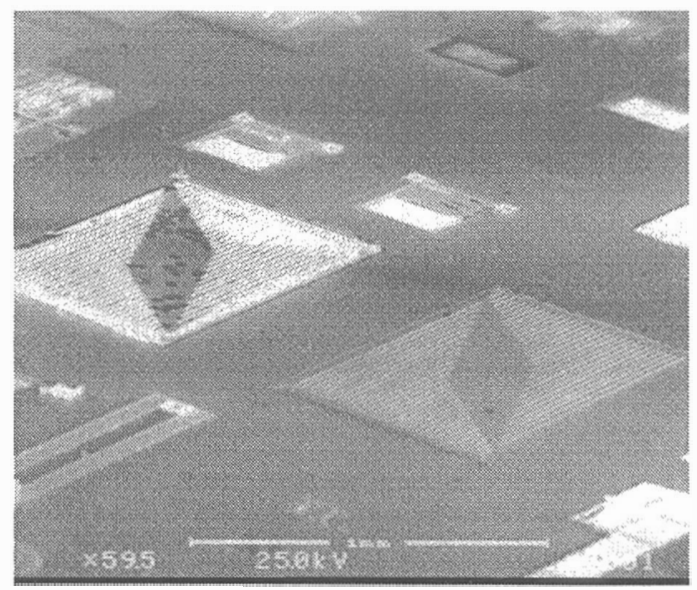

Figure 3: Selective deposition of copper on structures in desired areas on the chip. The bright structures imply copper deposited on polysilicon. 


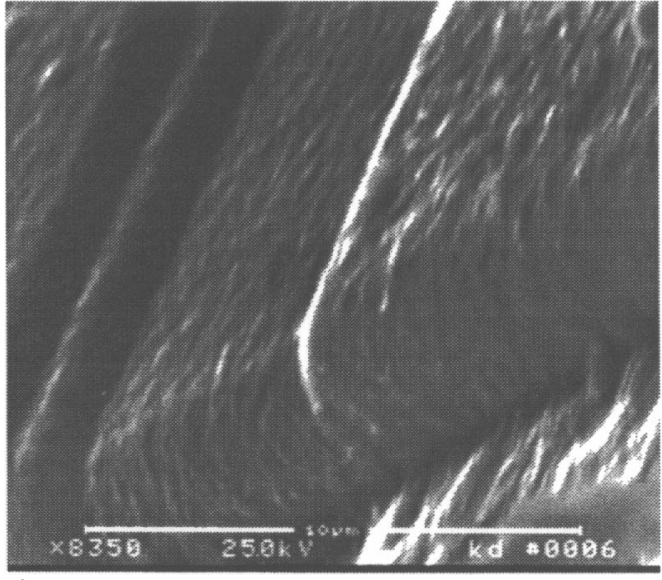

Figure 4: Selective deposition of copper on polysilicon. The oxide on the left-hand side of the polysilicon was protected during release. The right-hand side shows copper deposition. The copper is conformal to the polysilicon topography.

\section{CHARACTERISTICS OF COPPER}

For our work, the characteristics measurements we have performed include resistivity, deposition rate, grain size, roughness, and backside observation. The resistivity of electroless copper is measured by a Prometrix four-point probe instrument and is found to be $2.3 \mu \Omega-\mathrm{cm}$ when deposited at the temperature of $66^{\circ} \mathrm{C}$. As the deposition temperature increases, the resistivity decreases and approaches $1.8 \mu \Omega-\mathrm{cm}$. The deposition rate is found to be $55 \mathrm{~nm} / \mathrm{min}$ at the temperature of $66^{\circ} \mathrm{C}$. The deposition rate goes up to $120 \mathrm{~nm} / \mathrm{min}$ as the deposition temperature increases to $80^{\circ} \mathrm{C}$.

The surface morphology of the copper can be seen from a scanning electron microscope image of a sample with $400 \mathrm{~nm}$ of copper deposited (Figure 5). The rms surface roughness of the copper was measured to be approximately $20 \mathrm{~nm}$ over an area of $100 \times 100 \mu \mathrm{m}^{2}$ using the contact mode of atomic force microscope (AFM). The rms surface roughness of the in-situ boron-doped polysilicon underneath the copper was found to be about $10 \mathrm{~nm}$. Scanning over an area of $1 \times 1 \mathrm{~m}^{2}$, (Figure 6) we estimate that the average grain size of the copper to be $60 \mathrm{~nm}$.

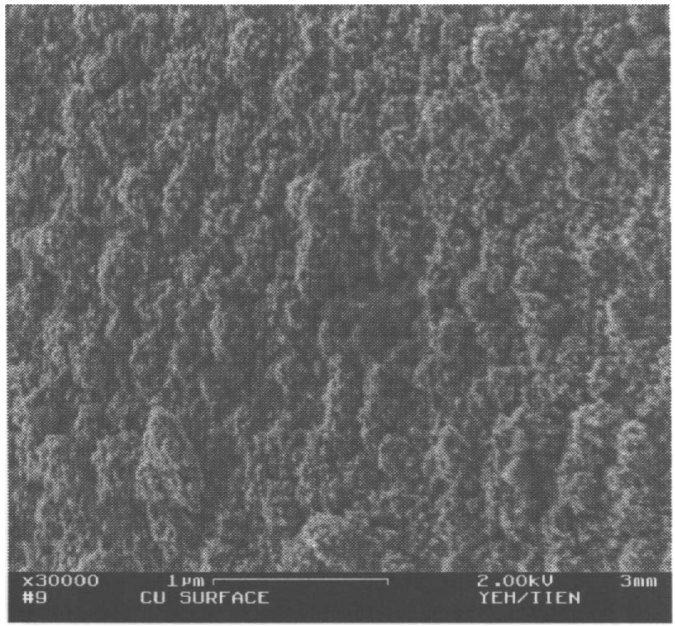

Figure 5: A SEM image of $0.4 \mu \mathrm{m}$-thick copper on the top of polysilicon.

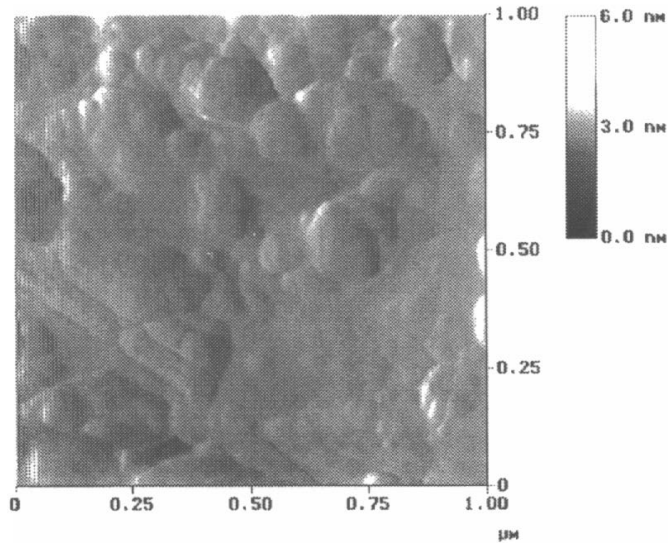

Figure 6: AFM surface scan of a sample with $0.4 \mu \mathrm{m}$-thick copper on it.

The electroless copper was conformally deposited on the sidewalls of polysilicon structures and exhibited the same microstructure as that on the topside surface (Figure 7). It was also found that the edges of etch holes or structures have higher deposition rate than other places. In particular, the edges on the topside surface tend to attract more and larger particles which may eventually block the transportation of copper ions and by-products in and out through etch holes.

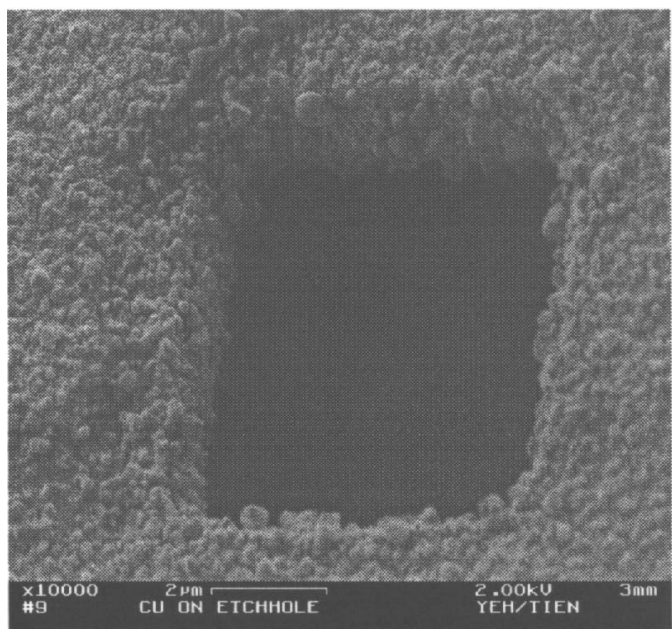

Figure 7: Electroless deposited copper around an etchhole.

We observed the copper deposition on the backside of polysilicon membrane with different size of etch holes and different spacing between the etch holes. At a deposition rate of $100 \mathrm{~nm} / \mathrm{min}$ for 2 minutes, copper aggregates form randomly within $5 \mu \mathrm{m}$ around etch holes. At a deposition rate of $30 \mathrm{~nm} / \mathrm{min}$, scattered copper aggregates start to link with each other as time progresses. There are three primary factors in the quality of the backside deposition: palladium contact displacement on backside; the ratio between the diffusion length and the gap between the backside and substrate; and the degree in which the edge deposition blocks the copper ion diffusion.

\section{FUTURE WORK}

Selective electroless copper plating has been used to encapsulate free-standing polysilicon structures. This method allows polysilicon surface micromachining to be used for applications which require high conductivity, particularly on all 
sides of low-stress structures. Using this technique, we will develop high-Q RF passive elements such as airgap capacitors, three-dimensional inductors, and mechanical switches for wireless communication applications. Cantilever beams encapsulated by copper can be employed to make an electrical switch which has copper-to-copper contact interface. This switch may have better performance than polysilicon switches without backside metal coating due to lower contact resistance and lower stiction.

For all these copper-coated devices, oxidation is an extremely critical issue. To prevent copper from oxidation, thin metal protective layers can be electroless deposited with a palladium activation right after the copper plating. Adhesion is also a critical issue in this process which will be studied further. For example, bubbling of the copper foil occurs occasionally because of low palladium activation concentration and no emission holes for hydrogen gas. The amount of activation can be optimized by controlling the palladium and HF concentration, and the activation time. Techniques such as a $400^{\circ} \mathrm{C}$ vacuum annealing can also enhance adhesion and uniformity.

The method has been used to deposit copper on both sides of a hinged plate that can be used in silicon micro-optical systems. Refinement of the deposition process parameters may improve the surface quality in terms of reflectivity and other metals may need to be considered. For instance, a micromirror reflective on both sides can be used in a bi-directional optical switch with two input fibers and two output fibers. The switching output of two input signals is controlled by the on/off position of the mirror.

\section{ACKNOWLEDGMENT}

The authors would like to thank the entire Cornell Nanofabrication Facility (CNF) staff for their support, Jocelyn Nee for her fabrication assistance, and Daryl Dagel and Hongrui Jiang for characteristic measurements.

\section{REFERENCES}

1. D. J. Young and B. E. Boser, "A micromachined variable capacitor for monolithic low-noise VCOs," Proc. IEEE Solid-State Sensor and Actuator Workshop, Hilton Head, SC (1996), pp. 8689.

2. L. J. Hornbeck, "Digital Light Processing ${ }_{\mathrm{TM}}$ for high-brightness, high-resolution applications," Proceedings of the SPIE - The International Society for Optical Engineering, vol.3013, pp. 27-40 (1997).

3. M. H. Kiang, et al., "Planarized copper interconnects by selective electroless plating," MRS Symposium, Vol. 260, pp. 745755 (1992).

4. Y. Shacham-Diamand, et al., "Copper electroless deposition technology for ultra-large-scale-integration (ULSI) metallization," Microelectronic Engineering, vol.33, no.1-4, pp. 47-58 (1997).

5. T. Kudrle, H. P. Neves, and N. C. MacDonald, "Microfabricated single crystal silicon transmission lines," to be published 6. M. C. Wu, et al., "Micromachined free space integrated microoptics," Sensor and Actuators A, Phys., Vol. 50, pp. 127-134 (1995).

7. N. C. Tien, et al., "Surface-micromachined mirrors for laserbeam positioning," 8th Intemational Conference on Solid-State Sensors and Actuators and Eurosensors IX. Digest of Technical Papers, Sweden (1995), Vol. 2, pp. 352-355
8. M. -H. Kiang, et al., "Actuated polysilicon micromirrors for Raster-scanning display," Transducers 1997 Digest of Technical Papers, Vol. 1, pp. 343-345.

9. H. P. Neves, T. Kudrle, J.-M. Chen, and N. C. MacDonald, "Characterization of electroless copper deposition for MEMS applications," to be published.

10. M. R. Houston, et al., "Self-assembly monolayer films as durable anit-stiction coatings for polysilicon microstructures," Proc. IEEE Solid-State Sensor and Actuators Workshop, Hilton Head, SC (1996), pp. 42-47. 